\title{
Microstructure and Mechanical Behavior of AlCoCrFeNi HEA Particles Reinforced 6063Al Alloy Matrix Composites
}

\author{
Shaofeng YANG ${ }^{1,2 *}$, Jianan WEN ${ }^{1}$, Jiao MO ${ }^{1}$, Hao LIU ${ }^{1}$, Jieyu SU $^{1}$, Yuheng MI $^{1}$ \\ ${ }^{1}$ School of Materials Science and Engineering, Nanjing Institute of Technology, Nanjing, China, 211167 \\ ${ }^{2}$ Jiangsu Key Laboratory of Advanced Structural Materials and Application Technology, Nanjing, China, 211167 \\ crossref http://dx.doi.org/10.5755/j02.ms.24209
}

Received 16 September 2019; accepted 31 December 2019

\begin{abstract}
Lightweight composites consisting of 6063 aluminum alloy matrix reinforced with AlCoCrFeNi high-entropy alloy (HEA) particles were fabricated by the powder metallurgy through hot pressing and hot extrusion under vacuum. A detailed microstructural characterization was carried out along with the analysis of mechanical properties. The results revealed that the observed uniform distribution of HEA powders and a good bonding strength resulted in an effective strengthening and increased plastic strain of the reinforced composite. The tensile properties of composites were effectively improved by the addition of 10 and $30 \mathrm{vol} \%$ of reinforcing HEA particles.

Keywords: metal matrix composites, high entropy alloy, interface bonding, mechanical properties.
\end{abstract}

\section{INTRODUCTION}

Aluminum matrix composites (AMCs) find a wide application as promising lightweight materials [1-3]. The mechanical properties of such composites, which have a ductile metal matrix, are improved by adding reinforcing nanoparticles, such as $\mathrm{SiC}$ or $\mathrm{Al}_{2} \mathrm{O}_{3}$, as well as carbon nanotubes. However, the advantages of ceramics, such as high stiffness and acceptable density, are counteracted by their poor wettability/bonding with the alloy matrix, which produces a series of problems such as weak interfacial bonding strength, porosity, as well as detrimental interfacial reactions [4]. This poor interfacial bonding mechanism may deteriorate the stress resistance and mechanical properties of composites. Despite significant efforts on the improvement of interfacial bonding between the ceramics and metal matrix, no breakthrough solution to this problem has been reported yet.

Multi-principal-element alloys, also referred to as high-entropy alloys (HEAs) because of the high entropy of mixing of alloying elements, have received a considerable attention from the scientific community in the last decade [5-7]. HEAs display lucrative properties, such as excellent corrosion resistance, high hardness, superior compressive strength, excellent wear resistance, hightemperature softening resistance, etc. However, like other metallic glasses and intermetallic compounds, these brittle materials have extremely limited plasticity under stress conditions, especially HEAs with the body-centered cubic (bcc) lattice that possess higher strength and hardness. Wang et al. [8] successfully produced Al-based metal matrix composites reinforced with $\mathrm{Mg}_{65} \mathrm{Cu}_{20} \mathrm{Zn}_{5} \mathrm{Y}_{10}$ metallic glass particles that were uniformly distributed along the composite volume and exhibited a good interfacial bonding with matrix. Recent studies on HEAs have shown that the content of $\mathrm{Al}$ element was the key

\footnotetext{
${ }^{*}$ Corresponding author. Tel.: +86-25-86118274; fax: +86-25-86118271. E-mail address: yangshf@njit.edu.cn (S.F. Yang)
}

factor for the formation of bcc solid-solution high-entropy alloy and directly influenced the alloy strength and hardness. Therefore, the brittleness of Al-containing HEA may have a good compatibility with a soft Al-based metal matrix. Given this, HEAs with bcc lattice may be good candidates for the replacement of ceramic particles as reinforcements of AMCs.

In this paper, the AlCoCrFeNi HEA particles were used as reinforcement in AMCs by Hot extrusion molding technology. The microstructure and mechanical properties were investigated by universal testing machine. A significant improvement of mechanical properties of the obtained composites was observed.

\section{EXPERIMENTAL}

The master alloy of the eutectic AlCoCrFeNi (elements in atomic ratios) was prepared from commercially pure elements (99.99 wt.\% for $\mathrm{Al}$, Co, and $\mathrm{Ni}$; 99.96 wt.\% for $\mathrm{Cr}$ and $\mathrm{Fe}$ ). Pre-alloyed AlCrFeCoNi spherical powder with a size distribution ranging from 20 to $60 \mu \mathrm{m}$ was provided by the vacuum induction melting and inert gas atomizer (VIGA). And 6063Al powders with $40 \mu \mathrm{m}$ mixed with pre-alloyed AlCrFeCoNi spherical powder. The consolidation of bulk samples was prepared by a uniaxial hot pressing at $453 \mathrm{~K}$ with the pressure of $600 \mathrm{MPa}$, with the following hot extrusion in the argon gas environment. During the molding process, powders were heated up to $723 \mathrm{~K}$ at a heating rate of $30 \mathrm{~K} / \mathrm{min}$, and then a pressure of $600 \mathrm{MPa}$ was applied for $10 \mathrm{~min}$. And then, the samples were extruded (with the extrusion ratio of $11: 1$ ) at $723 \mathrm{~K}$ with a pressure of $600 \mathrm{MPa}$.

The microstructural characterization of the crystal structure was carried out by a scanning electron microscopy (SEM, FEI Quanta 200, EDS, IE350MT) and Bruker D8 ADVANCE X-ray diffractometer (XRD) with a $\mathrm{Cu} \mathrm{K}-\alpha$ radiation target. Tensile tests were conducted using an Instron 5500 testing system. The Vickers hardness measurements were carried out on the consolidated sample 
with the load of 300 gf with the dwell time 10s using a Digital MicroHardness Tester HVS-1000.

\section{RESULTS AND DISCUSSION}

\subsection{XRD and microstructure analysis}

The SEM morphologies of the pre-alloyed AlCrFeCoNi spherical powders are shown in Fig. 1 a. It can be obviously seen that there are uniform spherical powders, which can improve the fluidity of powder in the printing process, and the surface of the particle is obviously equiaxial crystals after solidification (as shown in inset). The XRD pattern of the AlCrFeCoNi HEA is shown in Fig. $1 \mathrm{~b}$.

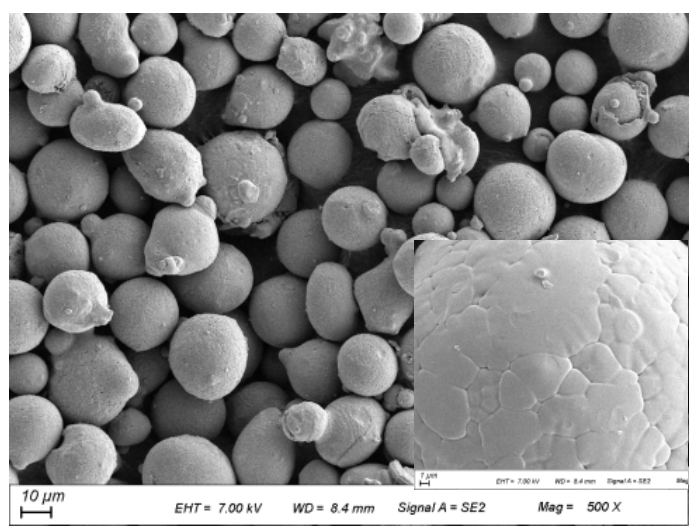

a

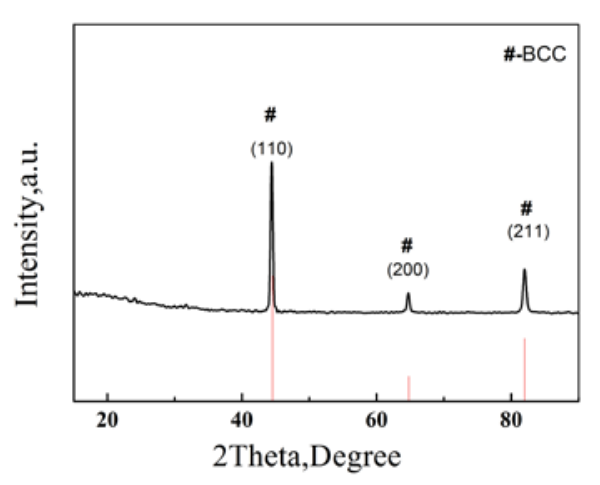

b

Fig. 1. a-SEM morphologies of AlCrFeCoNi HEA powders; $b$-XRD patterns of the AlCrFeCoNi HEA

It can be seen from the figure that the printed alloy is composed of simple BCC solid solution which similar to the $\mathrm{Fe}-\mathrm{Cr}$ solid solution (PDF\#34-0396). It is indicated that no complex multiphase forms in the alloys. The XRD pattern of the composite reinforced with 30 vol.\% of HEA is shown in Fig. 2. The pattern displays peaks corresponding to Al lattice.

Several physical parameters have been proposed to predict structural stability and phase formation in HEAs. Zhang et al [9] suggested a criterion for achieving solidsolution phases in HEAs using three parameters, $\Delta S_{\text {mix }}$ (entropy of mixing) $\Delta H_{\text {mix }}$ (enthalpy of mixing) and $\delta$ (atomic radius difference), as expressed below:

$\delta=\sqrt{\sum_{i=1}^{n} c_{i}\left(1-r_{i} / \bar{r}\right)^{2}}$ where $c_{\mathrm{i}}$ is the atomic percentage of the $i^{\text {th }}$ component; $\bar{r}=\sum_{i=1}^{n} c_{i} r_{i}$ is the average atomic radius; $r_{\mathrm{i}}$ is the atomic radius of the ith component.

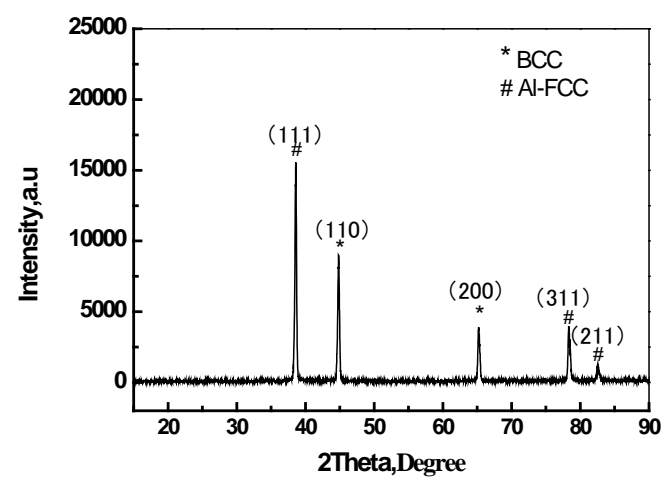

Fig. 2. XRD patterns of hot pressed Al-based composites with 30 vol.\% HEA particles

The thermodynamic parameter $(\Omega)$ is defined as:

$\Omega=\frac{T_{M} \Delta S_{m i x}}{\left|\Delta H_{m i x}\right|}$,

where, $T_{m}=\sum_{i=1}^{n} c_{i}\left(T_{m}\right)_{i},\left(T_{m}\right)_{i}$ is the melting point of the $i^{\text {th }}$ component.

The mixing enthalpy $\left(\Delta H_{m i x}\right)$ can be represented by:

$\Delta H_{\text {mix }}=\sum_{i=1, i \neq j}^{n} \Omega_{i j} C_{i} C_{j}$

where $\Omega i j\left(=4 \Delta H_{i j}^{m i x}\right)$ is the regular solution interaction parameter between the $i^{\text {th }}$ and $j^{\text {th }}$ elements; $c_{\mathrm{i}}$ and $c_{\mathrm{j}}$ are the atomic percentages of the $i^{\text {th }}$ and $j^{\text {th }}$ component. It is to be noted that $\Delta H_{\text {mix }} i j$ is the enthalpy of mixing, obtaining on the basis of Miedema macroscopic model for binary liquid alloys; and mixing entropy $\left(\Delta S_{\text {mix }}\right)$ can be represented by:

$$
\Delta S_{m i x}=-R=\sum_{i=1}^{n} c_{i} \ln c_{i}
$$

where $c_{\mathrm{i}}$ is the mole percent of component, $\sum_{i=1}^{n} C_{i}=1 ; R$ is the gas constant $\left(=8.314 \mathrm{~J}^{-1} \mathrm{Kmol}^{-1}\right)$.

The parameters, $\Delta S_{\text {mix }}, \Delta H_{\text {mix }}, \delta$ for the AlCrFeCoNi HEA are $\quad 13.09 \mathrm{~J} \cdot \mathrm{mol}^{-1} \mathrm{~K}^{-1}, \quad-12.78 \mathrm{KJmol}^{-1}, \quad 5.28$, respectively. The presence of the BCC phase implies that the mechanical alloying $\mathrm{AlCrFeCoNi}$ powder results in a more stable phase than FCC phase or intermetallic compounds in virtue of high mixing entropy.

Fig. 3 shows the SEM and TEM micrographs of the consolidated composites with 30 vol.\% HEA. As shown in Fig. 3 a, it can be clearly seen that HEA particles are uniformly distributed on the underground of the $\mathrm{Al}$ alloy matrix. The Fig. $3 \mathrm{~b}$ presents the interface between the HEA particle and the Al metal matrix. A clean and dissolving diffusion surface between the HEA particles and the matrix phases could be observed and the obtained 
composite materials have high density with few pores are visible. Especially at the interface, the $\mathrm{Al}$ matrix is tightly bound to the HEA reinforcement, and micro-reactions occur between the two phases, forming a lamellar layer of intermetallic compounds, suggesting that the AlCrFeCoNi HEA has good affinity with the matrix. Fig. 3 c shows the interface at a higher magnification. It can be found a diffusion reaction layer of $1-4 \mathrm{~nm}$ between matrix aluminum and high entropy alloy. It is well known that in solid phase sintering, the solid solubility between aluminum and transition group metal elements is very low, while the diffusion reaction between aluminum and iron and other elements requires a large solid solubility. The reaction layer in Fig. 3 c between aluminum alloy and high entropy alloy can be attributed to the following factors: the high entropy alloy solid solution state and the larger lattice distortion in high entropy alloys.

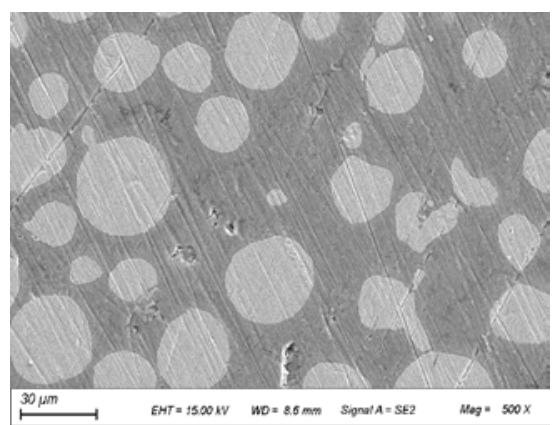

a

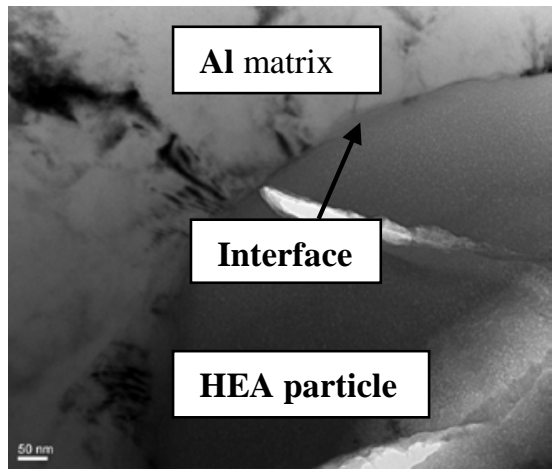

$\mathrm{b}$

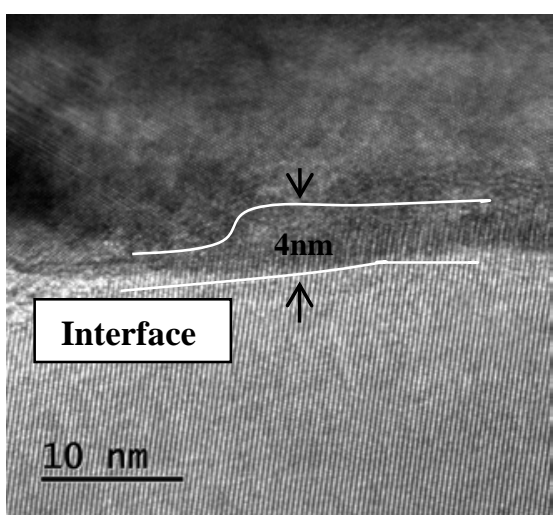

C

Fig. 3. Micrographs for the hot-pressed composites with 30 vol.\% of HEA reinforcement: a-SEM micrographs; b-the interface between the HEA particle and the $\mathrm{Al}$ metal matrix; $\mathrm{c}$ - the interface at a higher magnification
Appropriate interfacial reactions are beneficial to transfer loads and improve mechanical properties of composites [8].

\subsection{Mechanical properties}

Fig. 4 depicts the tress-strain curve of tensile specimen constructed under tensile loading to the hot-pressed 6063 $\mathrm{Al}$ alloy and composite materials with 10 and 30 vol.\% of HEA particles. The tensile samples are shown in the insert to Fig. 4 a. The hot-pressed $6063 \mathrm{Al}$ alloy has excellent tensile mechanical properties, namely, yield strength of $155 \pm 10 \mathrm{MPa}$, ultimate tensile strength of $190 \pm 10 \mathrm{MPa}$, and plastic strain of $14.2 \pm 0.5 \%$, which are higher than those of $6063 \mathrm{~T} 5$ alloy (145 MPa, $185 \mathrm{MPa}$, and $12 \%$, respectively). In contrast to cast samples from 6063Al alloys, the ones produced from hot-pressed and hotextruded powders have smaller crystalline grains and enhanced texture, which ensure improved mechanical properties of the metal matrix and make it lucrative for the AMC formation.
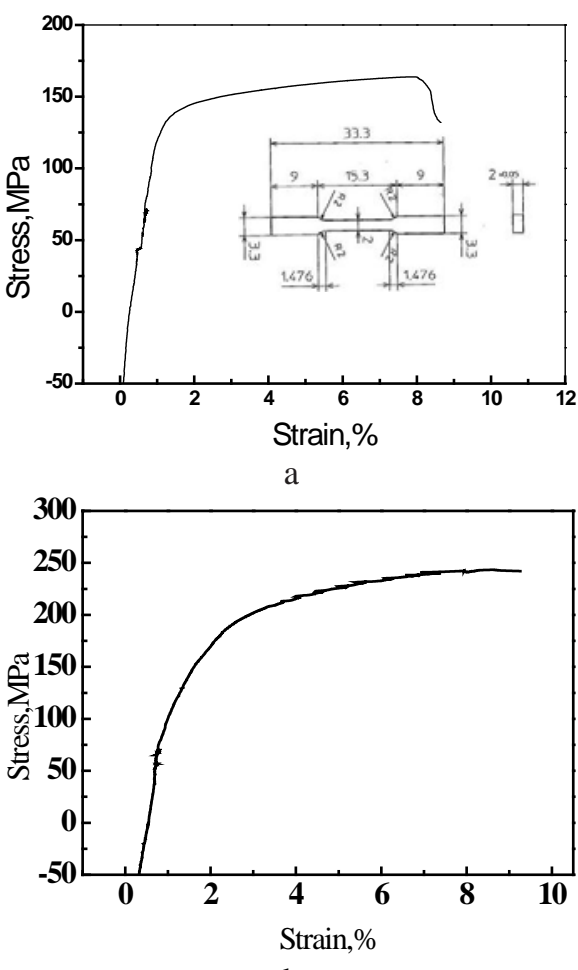

b

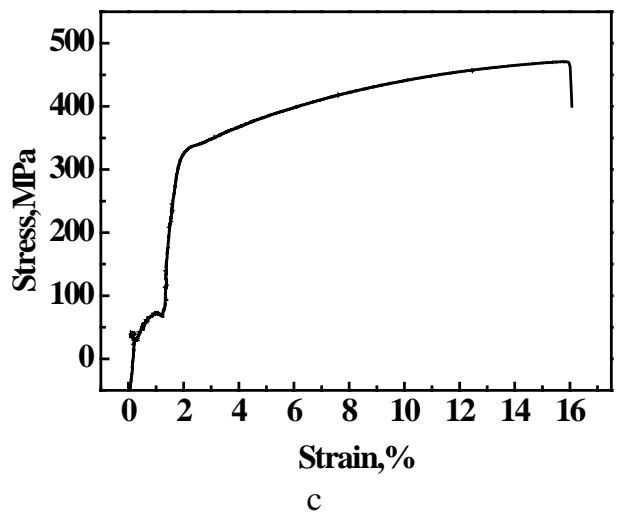

Fig. 4. a-stress-strain curves for $6063 \mathrm{Al}$; b-for the AMCs with 10 ; -30 vol. $\%$ of AlCrFeCoNi HEA particles 
The mechanical properties of hot-pressed $6063 \mathrm{Al}$ alloy are significantly improved by the $\mathrm{FeNiCoCrCuAl}_{2.8}$ HEA particles: the yield strength and ultimate tensile strength are increased from $155 \pm 10$ and $190 \pm 10 \mathrm{MPa}$ pure $6063 \mathrm{Al}$ alloy, respectively, to $185 \pm 10$ and $245 \pm 10 \mathrm{MPa}$ to $10 \mathrm{vol} \%$ HEA aluminum matrix composites. The samples with 10 vol.\% of HEA also obtains a considerable strain rate $(11.2 \pm 0.5 \%)$ before failure. With an increase in the volume fraction of HEA powders to $30 \mathrm{vol} . \%$, the yield strength and ultimate tensile strength further rose to $350 \pm 10$ and $475 \pm 10 \mathrm{MPa}$, respectively. Quite unexpectedly, the plastic strain of AMC with 30 vol.\% HEA is increased to $16.1 \pm 0.5 \%$. Reinforcing particles with high hardness greatly increased the yield strength of the AMC matrix. Besides the qualitative changes in the morphology, the quantitative estimation of the yield strength of AMCs reinforced with uniformly distributed hard particles can be provided as follows [10]:

$$
\sigma_{\mathrm{COH}}=M \varepsilon^{3 / 2} G\left(\frac{r f}{b}\right)^{1 / 2},
$$

where $M$ is a constant ranging from 2.6 to 3.7; $\varepsilon$ denotes the mismatch strain at the coherent interface; $G$ is the matrix shear modulus; $r$ is the particle radius; $f$ is the volume fraction of particles; $b$ is the modulus of Burgers vector of the matrix dislocation. The hardness and yield strength improvement accompanied by an increase in the volume fraction of AlCrFeCoNi HEA particles is shown in Table 1. As seen in Table 1, the yield strength values of AMCs calculated via Eq. 5 are in excellent accordance with the experimental results.

Table 1. Yield strength and hardness tabulation of $6063 \mathrm{Al}$ alloys and their composites

\begin{tabular}{|l|c|c|c|}
\hline & $\begin{array}{c}\text { Hardness, } \\
\text { HV }\end{array}$ & $\begin{array}{c}\text { Yield } \\
\text { strength, MPa }\end{array}$ & $\begin{array}{c}\text { Estimated by } \\
\text { Eq. 1, MPa }\end{array}$ \\
\hline 6063 alloys & 48.68 & 155 & \\
\hline $\begin{array}{l}\text { AlCrFeCoNi } \\
\text { HEA }\end{array}$ & 655 & $\begin{array}{c}254 \\
\text { (compression) }\end{array}$ & \\
\hline $\begin{array}{l}10 \text { vol.\% HEA } \\
\text { of AMCs }\end{array}$ & 116.45 & 245 & 234 \\
\hline $\begin{array}{l}30 \text { vol.\% HEA } \\
\text { of AMCs }\end{array}$ & 129.90 & 475 & 458 \\
\hline
\end{tabular}

Fig. 5 shows the corresponding fracture morphologies of the 6063Al alloy and AMCs. The tensile strain rate of the notched specimen was relatively low, the 6063Al alloy specimen fracture originated in the specimen center. The dominating macro- and microfracture mode was ductile: a pronounced necking as observed at the macrolevel, as well as multiple equiaxed dimples and a few tear ridges near the specimen edges at the microlevel, as shown in Fig. 5 a and b. The respective fractographic features of the AMC samples with different volume fracture of HEA particles are depicted in Fig. 5 c to f. In contrast to the fracture morphology of 6063 aluminum alloy, dimples in the composite correspond to peel-off sites of the reinforcing phase, tear ridges are observed at the reinforcing phase edges, and the fracture zone of the aluminum alloy matrix between the reinforcing phases contains equiaxed dimples. As compared to Fig. $5 \mathrm{~d}$ and $\mathrm{f}$, the positions of
AlCrFeCoNi HEA particles are shallower, and the interface between the particles and the matrix is less pronounced. Moreover, the fracture morphology of the aluminum alloy matrix is characterized by uniformly distributed tiny dimples. An increase in the HEA volume fraction from 10 to 30 vol.\% resulted in the growth of the yield strength and strain by 93.9 and $43.8 \%$, respectively. This improvement can be attributed not only to good wettability and, hence, a strong interfacial bonding strength, but also to the uniform HEA distribution in the matrix.

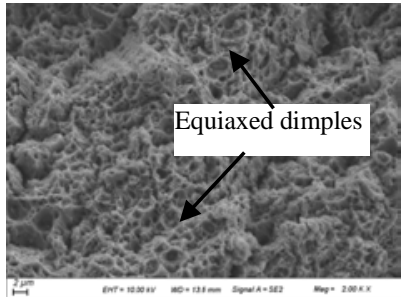

a

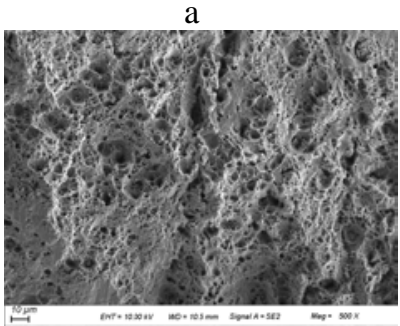

C

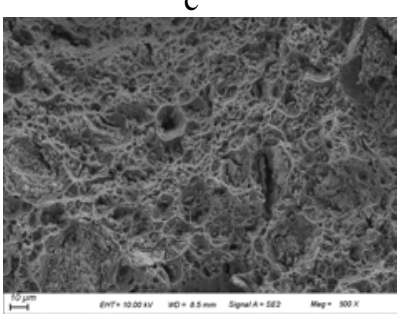

e

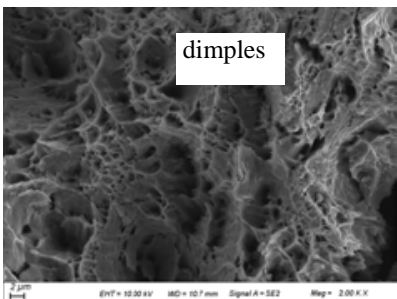

$\mathrm{b}$

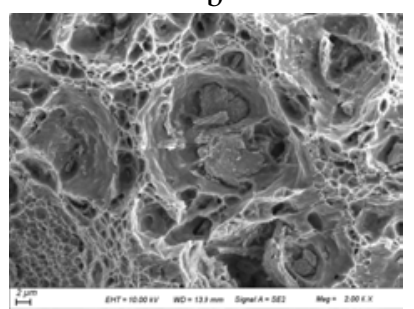

d

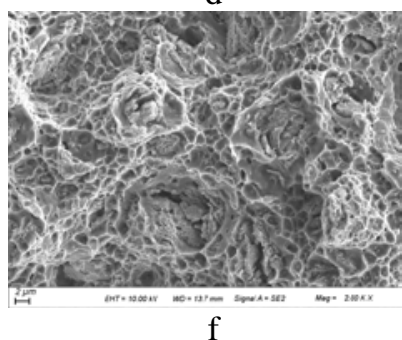

f
Fig. 5. Fracture images of the samples: a, b-6063 Al; c, $\mathrm{d}-f=10$ vol.\% HEA; e, $\mathrm{f}-f=30$ vol.\% HEA

\section{CONCLUSIONS}

6063Al composites reinforced with different volume fractions of AlCrFeCoNi particles were prepared by hot extrusion. The high-entropy alloy (HEA) systems are mainly composed of bcc solid solution. The HEAreinforced composites have good bonding with the matrix. The excellent mechanical properties of the high-entropy alloy composites are attributed to good wettability and, hence, strong interfacial bonding achieved between the matrix and HEA particle interface. The tested samples from composites with 30 vol.\% HEA exhibited excellent mechanical properties, namely the yield strength of $350 \pm 10 \mathrm{MPa}$, ultimate tensile strength of $475 \pm 10 \mathrm{MPa}$, and plastic strain of $16.1 \pm 0.5 \%$. Thus, as compared with the matrix, the hardness and yield strength of the composites under study were significantly improved, with a notable increase of plasticity.

\section{Acknowledgments}

This study was supported by National Natural Science Foundation of China [51671104], the Fourteenth batch of 
six Top Talent projects of Jiangsu Province [XCL-032], Challenge Cup cultivation Project for College students' Innovation Project in Nanjing Institute of Engineering [TP20180003].

\section{REFERENCES}

1. Shojaei, K., Sajadifar, S.V., Yapici, G.G. On the Mechanical Behavior of Cold Deformed Aluminum 7075 Alloy at Elevated Temperatures Materials Science \& Engineering A 670 2016: pp. 81-89. https://doi.org/10.1016/j.msea.2016.05.113

2. Otto, F., Dlouhý, A., Somsen, C., Bei, H., Eggeler, G., George, E.P. The Inflfluences of Temperature and Microstructure on rhe Tensile Properties of a CoCrFeMnNi High Entropy Alloy Acta Materialia 61 2013: pp. $5743-5755$. http://dx.doi.org/10.1016/j. actamat.2013.06.018.

3. Wang, Z., Scudino, S., Prashanth, K.G., Eckert, J. Corrosion Properties of High-strength Nanocrystalline Al84Ni7Gd6Co3 Alloy Produced by Hot Pressing of Metallic Glass Journal of Alloys and Compounds 707 2017: pp. $63-67$. http://dx.doi.org/10.1016/j.jallcom.2016.11.21

4. Fa, Q.C., Li, B.S., Zhang,Y. The Microstructure and Properties of (Fecrnico)Alxcuy High-Entropy Alloys and Their TiC-reinforced Composites Materials Science \& Engineering A 598 2014: pp. 244-250. http://dx.doi.org/10.1016/j.msea.2014.01.044

5. Zhang, Y., Zuo, T.T., Tang, Z., Gao, M.C., Dahmen, A., Liaw, P.K., Lu, Z.P. Microstructures and Properties of High-entropy Alloys Progress in Materials Science 61 2014: pp. 1-93. http://dx.doi.org/10.1016/j.pmatsci.2013.10.001

6. Fu, Z.Q., Chen, W.P., Wen, H.M, Zhang, D.L., Chen, Z., Zheng, B.L., Zhou, Y.Z., Lavernia, E.J. Microstructure and Strengthening Mechanisms in an FCC Structured Singlephase Nanocrystalline Co25Ni25Fe25Al7.5Cu17.5 High Entropy Alloy Acta Materialia 107 2016: pp. 59-71. http://dx.doi.org/10.1016/j.actamat.2016.01.050

7. Ogura, M., Fukushima, T., Zeller, R., Dederichs. P.H. Structure of the High-entropy Alloy AlxCrFeCoNi: fcc versus bcc Journal of Alloys and Compounds 715 2017: pp. $454-459$. http://dx.doi.org/10.1016/j.jallcom.2017.04.318

8. Wang, Z., Tan, J., Sun, B.A. Fabrication and Mechanical Properties of Al-Based Metal Matrix Composites Reinforced with Mg65Cu20Zn5Y10 Metallic Glass Particles Materials Science \& Engineering A 600 2014: pp. 53-58. http://dx.doi.org/10.1016/j.msea.2014.02.003

9. Okamoto, N.L., $\quad$ Fujimoto, S., $\quad$ Kambara, Y., Kawamura, M., Chen, Z.M.T., $\quad$ Matsunoshita, H., Tanaka, K., Inui, H., George, P. Size Effect, Critical Resolved Shear Stress, Stacking Fault Energy, And Solid Solution Strengthening in the CrMnFeCoNi High-entropy Alloy Scientific Reports 6 2016: pp. 35863. http://dx.doi.org/10.1038/ srep35863.

10. Wang. Z., Georgarakis, K., $\quad$ Nakayama, K.S. Microstructure and Mechanical Behavior of Metallic Glass Fiberreinforced Al Alloy Matrix Composites Scientific Reports 2016: pp. 1-11. http://dx.doi.org/ 10.1038/srep24384 